\title{
Chapter 4 \\ Beyond the Institutional Form: \\ Motivations for Collective Action
}

\subsection{Introduction}

The previous chapter described how globalisation, the erosion of embedded liberalism and social protection, and pressure on mutual solidarity between Member States have led to growing frictions in the European Union. These frictions have usually had a combination of causes: external events, internal choices, or the unforeseen consequences of compromises that turned out better for one country or one segment of the population than for another.

While such frictions have become almost a fixed pattern, they have undermined Europeans' support for the project of integration in its current form. For a more complete picture of the sources of these frictions and how they affect European integration, this chapter surveys the various different motivations for cooperation and the variety of institutional forms within the EU. The factors that cause the frictions are multifaceted and ambivalent, after all. To understand the differing and sometimes opposing trends, this chapter examines what goes on behind the institutional forms of European integration. Anyone who looks beyond these forms will discover that motivations for collective action play a crucial role. Examining them will give us a better understanding of what is happening in the EU today and the sources of its current problems. In this chapter, we visualise this approach in the form of a matrix that, besides the dimension of the institutional order, also considers what lies behind it: the dimension of collective action and the motivations for such action. Our visualisation is not meant to offer explanations or solutions. It should be regarded as a tool that acknowledges the underlying motivations of Member States when charting the possibilities and impossibilities of public tasks. Our approach also allows for a more precise assessment of where changes in European integration might be appropriate, where scope for further variation exists, and how it should be effectuated.

The appendix includes an exposition showing how the matrix presented in this chapter can be applied 'dynamically'. It places several urgent European issues, such 
as the free movement of services, the resettlement of asylum seekers and European border surveillance, within the matrix, using concrete examples of policy instruments to identify the push-pull forces at work. For example, it examines the content-based positions of these issues in the European field of influence by emphasising the 'why' behind them and by relating them to obstacles to and opportunities for other institutional approaches. This will help us to better understand the current discussions on the EU and to explore, more consciously and proactively, other approaches to cooperation.

\subsection{Introduction to the Matrix: Two Axes}

We often have high expectations of the EU. For example, we expect it to protect the Community against external threats, protect individuals against the negative aspects of globalisation, and take action in response to migration and climate issues.

Our projection of what the EU should or can do assumes that it can deliver public goods that the Member States are unable to produce on their own, for example a stable and fair socio-economic order, a sustainable living environment, or international security and freedom. It is not necessarily a given that the EU should take over its Member States' tasks, however. The point is to produce the desired public goods reliably, not to confirm European institutional structures. However, producing those goods often requires a level of organisation and teamwork beyond that of intergovernmental cooperation. This means that the EU's institutional structures should be derived from European public tasks (linked to desired public goods), and not the other way around.

Despite this, we often see the institutional order at the heart of European policy. Policy discussions focus on the form of cooperation - which Member States are participating and which are not and what is the corresponding transfer of competences? The European public tasks that are to be fulfilled-i.e. the content-are thus relegated to the background. It is only when the process of European integration shifts focus from form to content, in other words from institutional order to European public tasks, that the 'why' of collective action becomes apparent. That then provides the basis for considering which institutional forms are or are not possible.

This book uses the matrix below to illustrate the possibilities and impossibilities of a number of European public tasks. The purpose of the matrix is to cross the possible institutional order within European cooperation (horizontal axis) with the motivations for collective action (vertical axis) and to investigate how they relate in the production of public goods. We begin by providing theoretical underpinnings for the concept of European integration as a collective action. The following paragraphs explain the axes and cells in greater detail. 


\subsection{European Integration as a Collective Action}

According to Olson $(1965),{ }^{1}$ the more members there are in a group, the less likely that they will be able to spontaneously advance their common interests through collective action. This is true even where the group is unanimous about the public good and the method to be used to produce it. In the world of European integration, this conclusion - that spontaneous collective action is virtually impossible - implies the following.

As the number of Member States increases, it becomes less and less likely that individual Member States will be prepared to help achieve the EU's official, established goals. In other words, Member States will aid in achieving those goals only if the EU offers them enough selective incentives. Specifically, this means that European integration must hold out the prospect of penalties and rewards to each Member State from which non-members can be excluded.

One important qualification here, however, is that an organisation-like any other form of collective behaviour - can also achieve official goals without any of its members aiming to achieve those goals through its actions. The same can be said of the EU. It is quite conceivable (and there is empirical evidence in specific cases) that the EU can attain the official goals of European integration without its Member States themselves pursuing such goals. For example, the history of European integration offers us frequent examples of Member States that, despite unequivocally putting their national economic interests first, promoted prosperity by opening up their national economies to one another and accepting supranational enforcement of such reciprocity. Individual considerations and official organisational goals are not, by definition, at odds with one another.

Since the 1990s, a distinction has been made in the literature on collective action between the 'logic of appropriateness' and the 'logic of consequences' in interpreting individual modes of action. ${ }^{2}$ In this book, an actor or group of actors-here, EU Member States - that adhere to the 'logic of appropriateness' will take decisions that follow rules of appropriate or exemplary behaviour. In such behaviour, normative considerations outweigh cost-benefit considerations.

Institutions that refer to the 'logic of appropriateness' add an ethical or moral dimension to their practices and the expectations that they raise. In the reality of the EU, they see an idealistic level of solidarity as the desired mode of action for fulfilling European public tasks. But this mode of action has its downside as well. When put forward as a decisive argument for cooperation, the 'logic of appropriateness' has certain moral and ethical overtones that risk its being perceived, at some stage and within a certain institutional order, as a straitjacket without adequate democratic underpinnings.

The alternative is 'the logic of consequences', i.e. cost-benefit analyses based on individual self-interest or the collective interest. When this highly rationalistic mode of action prevails, the institutional order that emerges is regarded as an aggregate of individual interests achieved through processes of negotiation and coalition 
formation - and not much more than that. Cooperation is based on rules governing these processes, rather than on norms and values.

The two 'logics' need not be mutually exclusive. They can be regarded as the extremes on a continuum of modes of action. This continuum runs from a laser-sharp focus on national interest or autonomy at one end to idealistic interstate solidarity at the other, with hybrid forms such as 'situational or ad hoc solidarity' in the form of 'reciprocity' in between. The two logics can also reappear in very different types of agreement, ranging from mandatory rules to calls for more solidarity, which together create a framework of checks and balances for cooperation (see for example the work of Ostrom ${ }^{3}$ and the WRR report Publieke zaken in de marktsamenleving ${ }^{4}$ ). Issues of European integration, which are by definition complex and multi-faceted, require the Member States to constantly consider this entire spectrum of options, although it is scarcely visible as such, if at all. Its breadth and significance almost always fades from view when officials attempt to explain the course of events and the decisions taken. That is often counterproductive, because it narrows the debate on European integration to one of 'more or less Europe', rather than focusing on the question of 'why?' and 'what kind of Europe do we want to live in?' It also obscures our view of the public tasks that are ultimately at stake (see the first section of this chapter). The problems that this creates have become more and more obvious in recent years.

The creation of the European Communities, and subsequently of the EU, was based on the understanding that vital public tasks can be better, or in fact only, fulfilled by a permanent alliance that has its own political legitimacy. Although the supranational nature of European legislation, governance and court rulings was accepted in the 1950s and 1960s, direct political legitimacy took longer to achieve. Important steps have been taken towards democratisation: a European Parliament whose members are elected directly by the people was founded in 1979; European citizenship was established in 1993; and the European Parliament was given almost full co-legislative competences in 2009. Nevertheless, the results of various referendums - most recently on the Ukraine-EU Association Agreement in the Netherlands and on Brexit in the UK - show that alienation and centrifugal forces are impairing the European project more than ever before.

This experience is yet another reason why the EU should avoid once more embarking on an institutional reconstruction, as it did when it founded the European Convention that produced the failed Treaty establishing a Constitution for Europe. Nor is institutional destruction recommended; the United Kingdom is already experiencing major difficulties as it cancels its membership of the EU. Far too little thought has so far been given to the possibility that the dissonance between the EU and its citizens is caused precisely by its failure to fulfil its public tasks. After all, when citizens feel abandoned, the authorities with which they are least familiar-in this case, those of the European Union - are the first to bear the brunt of their mistrust and rejection. ${ }^{5}$ 


\subsection{Motivations for European Collective Action}

It is important to acknowledge how diverse the expectations, interests and preferences involved in European integration are. After all, the motivation, public interest or normative framework that colours how Europeans view integration determines which policies will and will not have their support.

The motivations for European collective action differentiated in this book form a type of continuum. In the matrix below (Fig. 4.1), they are shown on the vertical axis.

\section{(1) National autonomy: Self-governance is critical.}

Motivation: Cooperate with other countries only when unavoidable.

In this approach, the aim is to be as independent as possible from other states or other actors, and to retain as much power as possible to make one's own laws and rules. A state that takes this approach to European cooperation does not, in principle, think cooperation offers enough advantages to relinquish some of its power of self-governance. It will therefore minimise European cooperation and only cooperate if there is no other option. It is difficult to reconcile this approach with structural cooperation, interstate solidarity and supranational institutions.

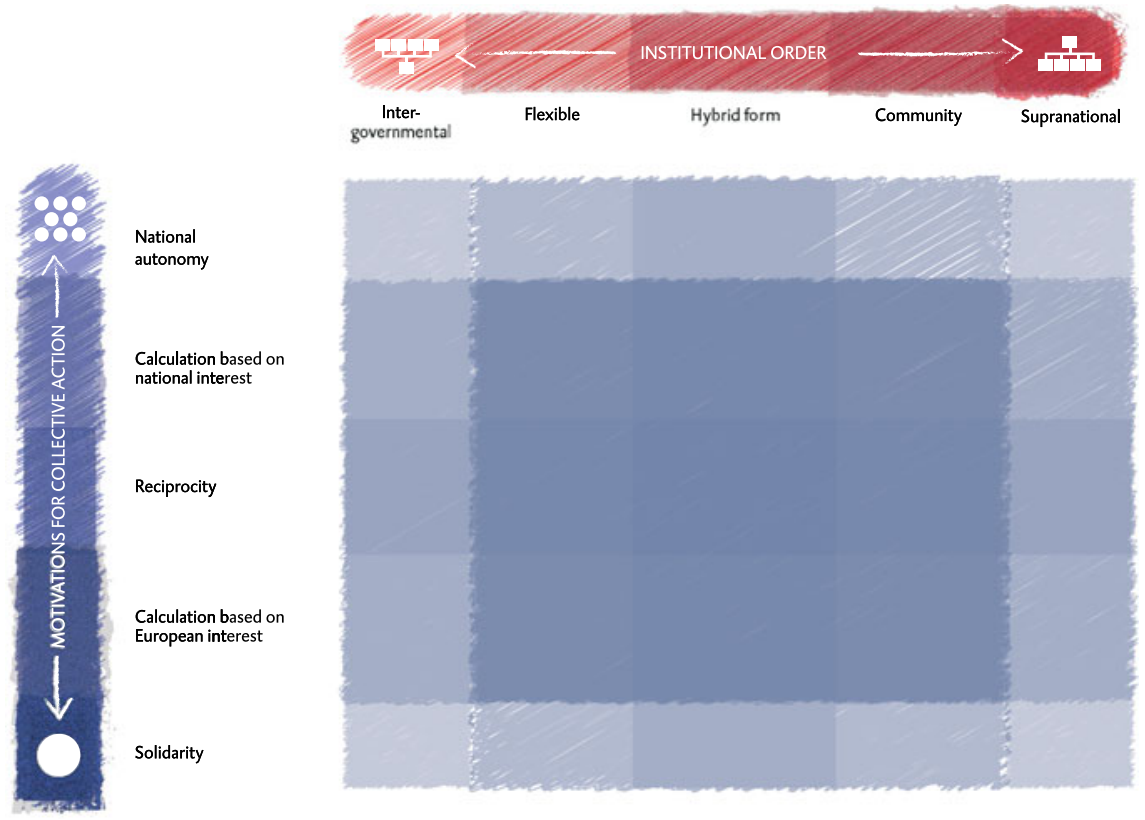

Fig. 4.1 Introduction to the matrix 
Example: Agreements on cross-border issues, such as inland shipping on rivers that transcend national borders.

\section{(2) Calculation based on national interest: Recognising that cooperation can be advantageous.}

Motivation: The advantage is immediately evident.

In this approach, European cooperation is accepted if it is advantageous to the individual state. That means that the state has estimated or agreed in advance what cooperation will yield. The advantage may be short-term or long-term in nature, but the state is more likely to go after short-term goals and associated advantages, as they are generally more predictable. The behaviour of the cooperating partners must also be stable. Predictability and quantifiability are crucial in this form of cooperation, but solidarity is not required.

Example: Pooling of defence equipment.

(3) Reciprocity: One good turn deserves another, playing by the rules to create a level playing field.

Motivation: Surrender policy autonomy in favour of market access and expected convergence.

In this approach, states decide to cooperate in Europe based on the notion of reciprocity. They are prepared to delegate their autonomy in a policy domain to supranational institutions because it will ultimately benefit them to do so. This means that certain 'losses' (material or in terms of autonomy) are accepted in the expectation that they will be compensated in the long term. In anticipation of this positive result, they invest in long-term cooperation. Sahlin $(1972)^{6}$ refers to this form of reciprocity as 'balanced' or 'symmetrical' reciprocity. It requires all the participating partners to comply with the rules as they have been agreed. Compliance and enforcement are crucial and are (in part) entrusted to supranational institutions, to avoid 'free riding' problems. After all, collective standards lose credibility as soon as certain participants cease complying with the agreements. Situations are conceivable in which a certain degree of solidarity is required to correct distortions in reciprocity.

Example: Opening the market to goods and services from other Member States and mutual recognition.

(4) Calculation based on European interest: Absorbing possible individual losses for the good of the greater whole.

Motivation: The collective advantage is immediately evident.

In this approach, European cooperation is taken a step further on the assumption that it is advantageous to all the partners as a group. The expectation is that the collective benefits of cooperation will ultimately accrue to the individual states as well, even though it may be detrimental to national interests in the short term. 
Example: The European Commission negotiates in the WTO on behalf of its Member States. A single, strong economic bloc is better than several small European states on the world stage. Another example is the asylum quota proposed by the European Commission in response to the refugee crisis.

\section{(5) Solidarity: Interstate solidarity as a principle. Making sacrifices for a higher purpose.}

Motivation: Idealistic solidarity and values.

In this approach, the larger whole serves a higher purpose than merely meeting national or material goals. Individual losses are accepted, and the losses of one or more partners are also borne by the others. The transfer of autonomy is inherent and may be necessary to enforce idealistic solidarity. The general, overarching aim is to maintain cooperation in anticipation of the tangible and intangible benefits that it will bring, including peace, human rights and social cohesion.

Example: Structural and cohesion funds to reduce disparities in prosperity between Member States and regions.

\subsection{Institutional Order}

Multiple institutional orders co-exist in the process of European integration. We go through them in this section to clarify our matrix. It is important to note that these are institutional forms whose basis lies in the decision-making method and the participating Member States. In other words, a categorisation of institutional orders offers a simplified version of reality. It serves to illustrate existing tensions concerning European public tasks and to show that such simplification does not lead to solutions. We have omitted various types of legislation (regulations and directives) as parameters from the categorisation.

This approach makes it clear that other issues play a role in the background, for example different (interpretations of) motivations for collective action, but also that variations are possible which are not immediately obvious. In the matrix above (Fig. 4.1), the various institutional orders can be found on the horizontal axis. We begin our description of this axis with the two idealised extremes on the left and right. We then look at the intermediate forms.

The two extremes:

\section{(1) Intergovernmental: Agreements are reached by consensus or unanimity.}

In this framework, agreements are made between governments to advance cooperation on a particular issue. There is no interference from institutions to which the cooperating states are subordinate; competences are not transferred and are retained at the national level at all times. Decisions can thus only be taken after full agreement has been reached, and they require the consent of all participating 
countries. States therefore have a right of veto on each issue, guaranteeing their full policy autonomy.

Example: Past cooperation within the EU's second and third pillars (and prior to that, within the framework of TREVI)

(2) Supranational: Only supra-state agreements and supra-state enforcement.

This institutional form involves the complete transfer of national policy autonomy to the supranational institutions of the European Union. In a hypothetical variant where this framework would apply to all policy domains, there would be a federation into which the Member States, as federal states, have been absorbed. Enforcement, initiation, democratic legitimacy and oversight of European policy implementation would be entrusted to supranational institutions, regulatory bodies and a supra-state parliament. Variations whereby Member States would or would not participate are not possible in this form of cooperation.

Example: The competences of the Commission in certain matters, such as competition policy or international trade, and the ECB come closest to this institutional framework

The intermediate forms:

(3) Community: Member States play a greater role in concluding supra-state agreements.

\section{All EU Member States participate.}

The cooperation established within the Community framework applies equally to all participating Member States and is based on (1) supranational institutions as initiators and guardians of the Treaty order, (2) qualified majority voting in the Council as the representation of the Member States and (3) co-decision-making by the European Parliament. As such, it is the same as the ordinary legislative procedure. Community cooperation differs from the supranational institutional framework in that it is possible for Member States to form blocking minorities, for example in the Council. It differs from the flexible arrangements (described below) in that all EU Member States participate in the Community. Variations whereby Member States do or do not participate are impossible in this form of cooperation.

Example: Internal market

\section{(4) Flexible: Differentiated arrangements based on participating Member States and decision-making.}

The flexible institutional framework allows states to decide, by policy domain, whether or not they wish to participate. Decision-making can take place both through intergovernmental arrangements and under the ordinary legislative procedure. This framework accommodates differentiated cooperation, such as opt-outs in certain areas, differing degrees or speeds of integration (variable-geometry and multi-speed Europe), lead group or sub-group formation, or closer cooperation. 
Example: Common European Asylum System (CEAS)

(5) Hybrid form: Encompasses all of the foregoing institutional elements.

The institutional framework described here as a 'hybrid form' has intergovernmental, supranational and Community elements, and is also flexible, with opt-outs permitted in certain areas. This institutional framework comes closest to the description of the current EU as a whole.

\subsection{Conclusion: Community Cooperation and Its Limitations}

The institutional order that has traditionally been appropriate for European integration differs from other forms of international cooperation. This difference is particularly noticeable in how the EU institutions cooperate with one another in the ordinary legislative procedure (the European Commission, the European Parliament and the Council). Adhering to the Community method of cooperation reinforces a tendency to seek solutions through deeper integration and uniformity, by having all Member States participate. It is a tried-and-tested formula in the history of European integration. Based on this 'policy rationality', motivations for collective action are then identified, often by appealing to an overarching European interest and interstate solidarity (see the vertical axis).

There is growing public and political resistance to closer European integration based on this policy rationality. Increasingly, political circles at national level advocate moving away from the EU (seeking solutions in the institutional orders located more to the left on the horizontal axis of the matrix). These new arguments correspond with a shift in the motivations for collective action towards more national autonomy, evident in the politics of almost all Member States (see the vertical axis).

Applying the matrix to the current reality reveals a critical fault line in European integration. If we take Community cooperation and the associated policy rationality as our basis, then we soon arrive at the following motivations for collective action: 'calculation based on European interest', 'solidarity' and 'reciprocity'. These motivations are often based in part on 'the logic of appropriateness' and correspond with the Community and supranational institutional orders, or possibly a hybrid form. In Fig. 4.2, the blue arrows pointing to the bottom right-hand side of the matrix visualise the trend induced by Community cooperation and the associated policy rationality.

The phenomenon of 'democratic alienation' in response to European integration is the opposite of this, in a certain sense (see Chap. 3). It manifests itself as a desire for maximum autonomy on the part of the national state. The Brexit campaign's 'take back control' slogan was a poignant example. 'Calculation based on national interests' can also serve as a motivation for collective action when political 


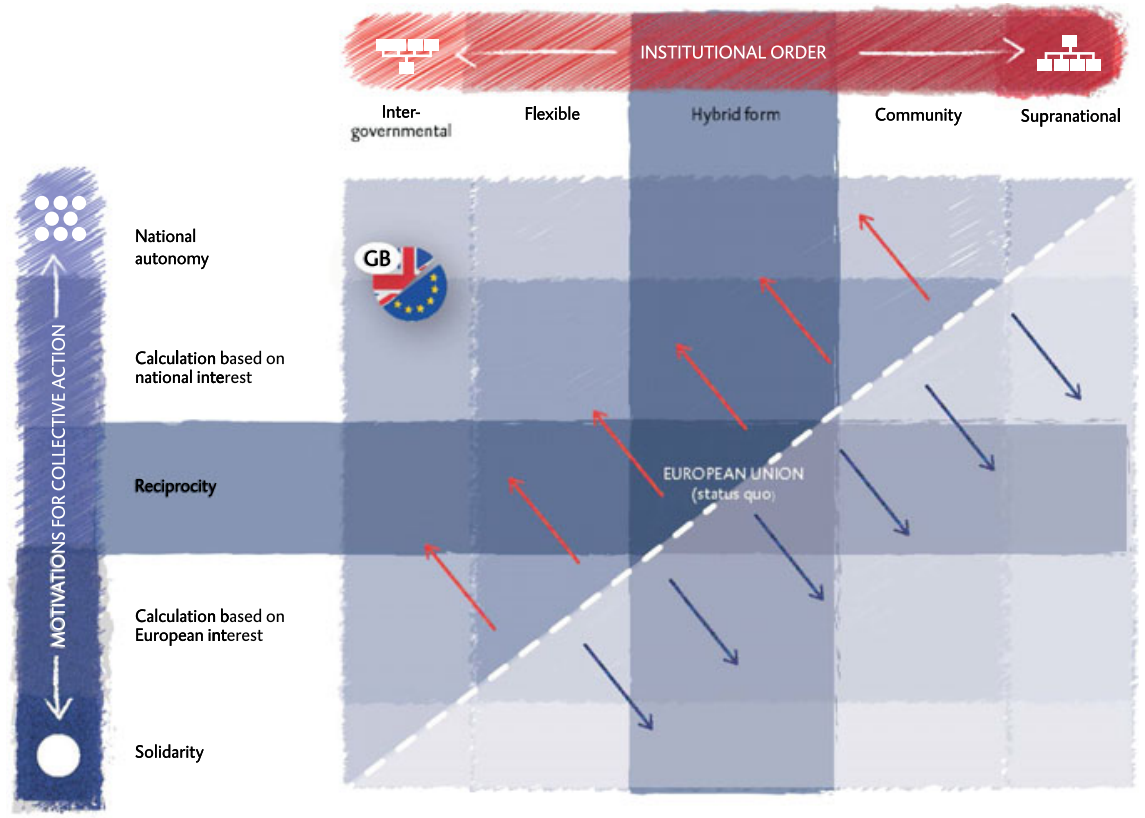

Fig. 4.2 Matrix of opposing trends

legitimacy is perceived to be lacking because it involves cooperation solely in the pursuit of individual short-term interests, something that is usually easier to justify in the domestic politics of the Member States. These two motivations are based on the 'logic of consequences'. They can usually only be advanced through an institutional order that takes the form of intergovernmental or flexible cooperation with a number of like-minded Member States. In Fig. 4.2, the red arrows pointing to the upper left-hand side of the matrix visualise the trend towards greater autonomy.

The original concept behind the European Communities involved the pursuit of free competition and a level playing field in a European single market. This European legal order would make it possible to remove obstacles to the common market without completely dismantling social protection in national legislation associated with the movement of goods, persons, services and capital. Social protection would also be guaranteed by harmonisation. Within this legal order as established by the Treaty of Rome, the notion of reciprocity (and hence the expectation of convergence), combined with Community cooperation, guided the evolution of European cooperation. See Fig. 4.3 for the visualisation.

The transition to the Maastricht order in 1993 cast European integration into the shape of the European Union. In the EU, the main institutional order increasingly evolved into a hybrid form that now includes supranational, Community, intergovernmental, but also flexible elements. The overall approach of reciprocity 


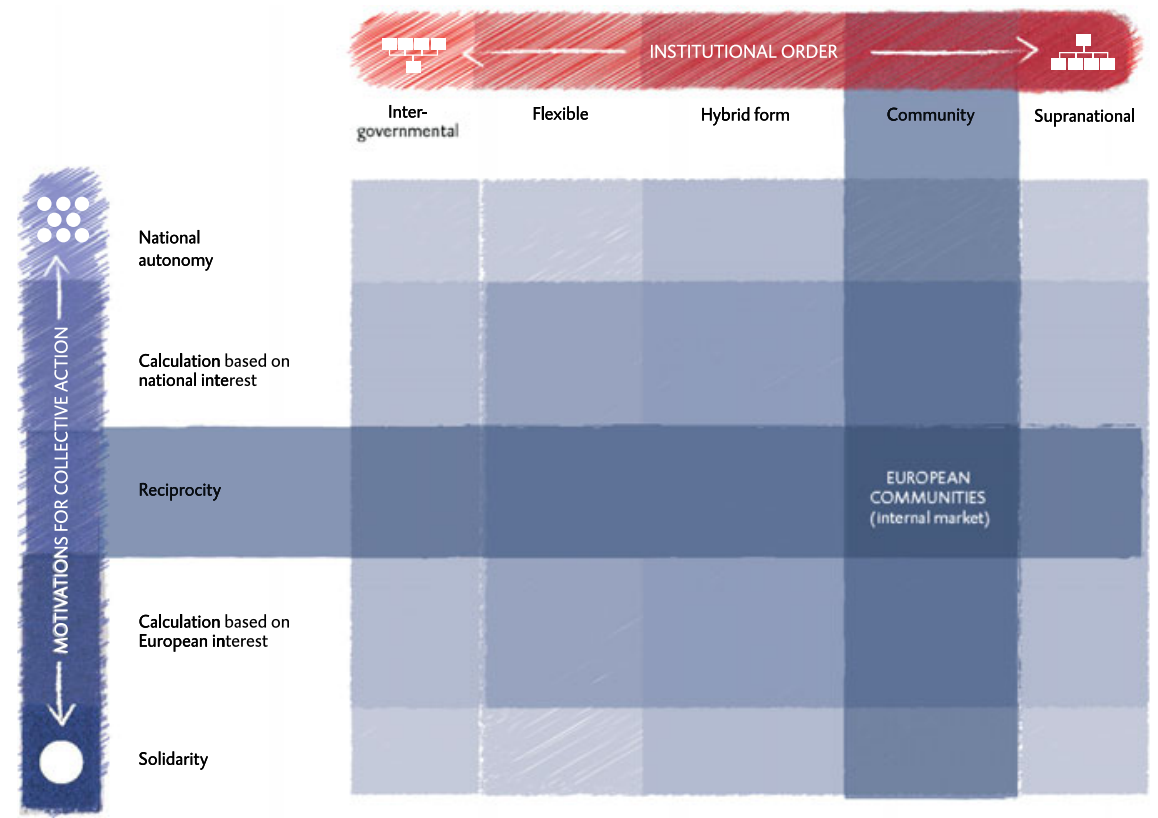

Fig. 4.3 Matrix showing the position of the European Communities

remained unchanged, however, and is still at the heart of Europe's self-image and how it handles policy measures.

Figure 4.4 shows that, in its present form, the EU is positioned precisely in the middle of the diverging trends described above. The opposing forces are at their strongest there, largely because EU Member States have a range of different motivations for collective action, often due to differences in how they prioritise public interests. Oftentimes, the motivations are neither recognised nor acknowledged, however. Instead, they are forced into the straitjacket of mutual recognition (in the expectation that this will encourage ever greater harmonisation and convergence) and 'playing by the rules'. All the while, the EU's institutions remain focused on Community cooperation with all the Member States. The frustrating inertia to which this leads may, in the long run, be detrimental to EU unity, as Brexit has recently demonstrated (Fig. 4.5). ${ }^{7}$

There are alternatives, however, that become possible by consciously allowing for more variation.

The matrix introduced in this chapter explains (1) the motivations for collective action and (2) the existing forms of institutional organisation within the process of European integration, and shows how the two relate. As we cautioned, this is a simplified version of reality. Significantly, what the matrix does not show is that even if different Member States choose the same motivation for collective action, they may have based that choice on completely different interpretations of the 
4 Beyond the Institutional Form: Motivations for Collective Action

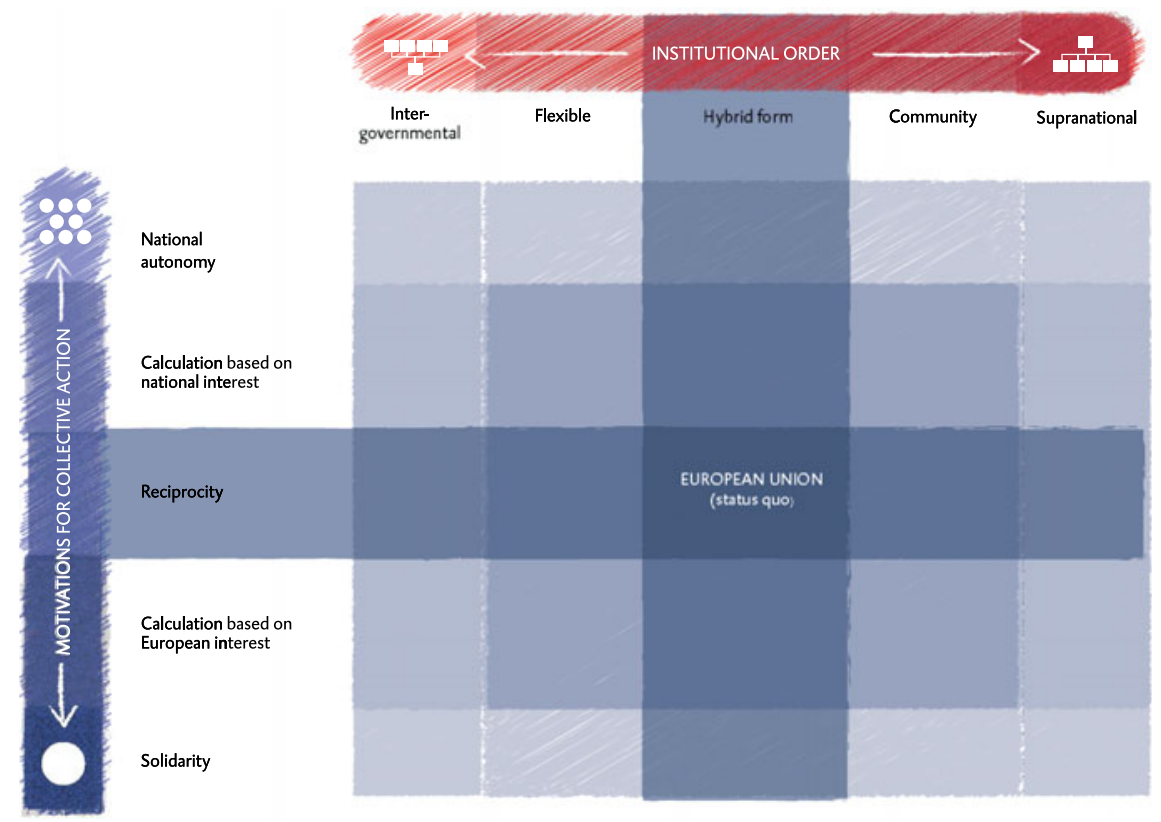

Fig. 4.4 Matrix showing the position of the European Union

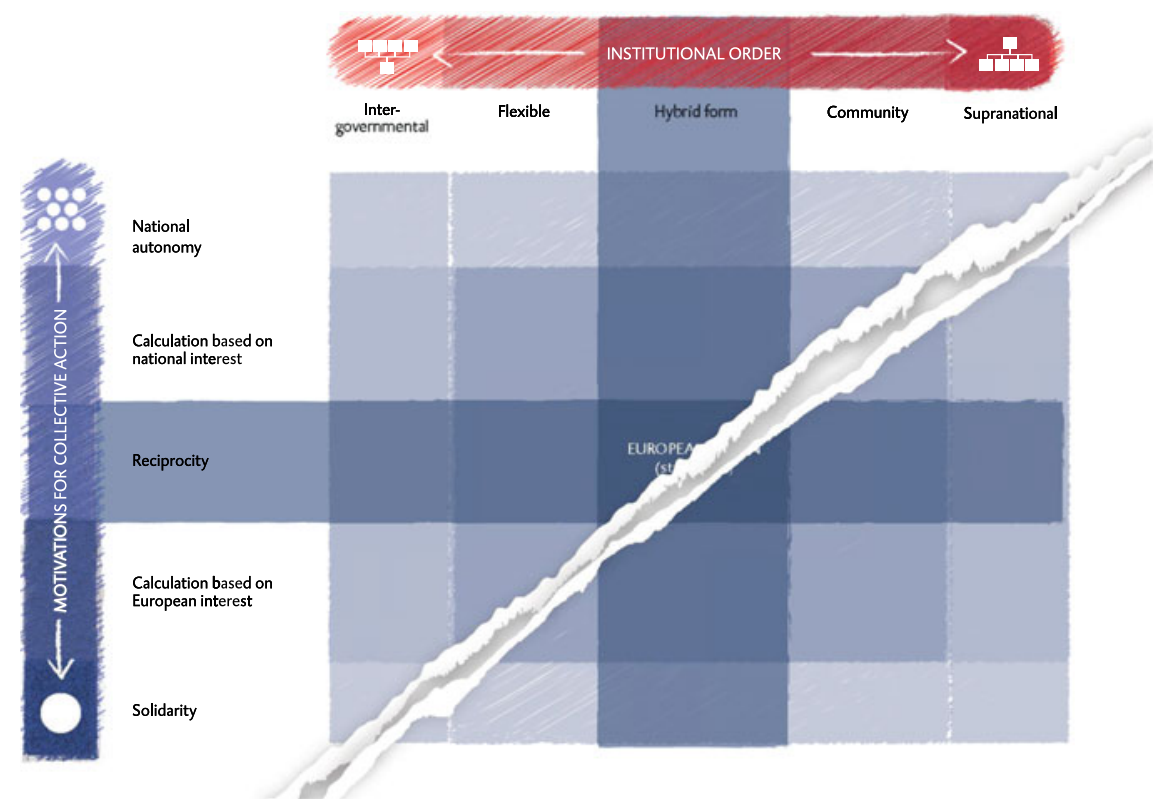

Fig. 4.5 Matrix of fault lines 
situation in question. This is particularly important with regard to motivations suggesting a constructive attitude towards European solutions. For example, two Member States that have the same motivation may be pursuing two different public interests or have different priorities within those interests.

In such a case, even when Member States share the same motivation for collective action, it may be impossible to arrive at a constructive European policy because the underlying interpretations differ too much. If we include such differences in interpretation in our analysis, then we get the following new option on the vertical axis of the matrix: Member States have the same motivation, but based on different interpretations of the situation. This is the third possibility alongside the more obvious ones in the matrix, namely 'Member States have the same motivation for collective action (and therefore interpret the situation in the same way)' and 'Member States have different motivations'.

When the motivations for collective action differ, scope for cooperation can be created by allowing variation in membership and/or the decision-making procedure. This is already apparent in the various 'flexible' and 'hybrid' institutional orders on the horizontal axis of the matrix and fits in with its set-up (which is based on membership and decision-making procedures as defined for the various institutional orders). However, variation in membership and/or decision-making is not enough in the third option, in which the motivation is the same but the underlying interpretations (which Member States use to defend their chosen motivation) differ. In that case, variation must be sought along a third dimension, in addition to membership and decision-making, namely the content of the relevant policy. One way to do this is to work with minimum standards and allow variation beyond that minimum (instead of seeking harmonisation). Even in the current quest for methods to strengthen the euro area and emu, variation in policy content offers scope for arriving at innovative solutions within the existing Treaty frameworks. The appendix provides a number of examples illustrating the above.

The EU's current problems thus demand that we not only break away from the notion of reciprocity and Community cooperation, but also that we examine the option of 'flexible' arrangements more closely by exploring the possibility of variation in policy content. The following chapter will reveal that 'policy variation' has existed since the founding of the European Communities, but has not always been recognised as such. We see this at the very heart of the Union, the internal market. There are no opt-outs there, no lead groups being formed, but ratherthanks in part to national discretion in policymaking - a continuous balancing of European public interests, for example between the four freedoms and other fundamental values arising from the embeddedness of European integration in social and human rights. The following chapter explores the theme of variation in more detail and analyses what forms of diversity in cooperation already exist in Europe. It examines existing variation practices in the internal market from a legal perspective, in particular with regard to the political legitimacy of variation in policy content and its significance for the four freedoms. 


\section{Notes}

1. Olson (1965).

2. March and Olsen (1995).

3. Ostrom $(2009,2010)$.

4. WRR (2012).

5. In three areas crucial to European societies, integration stalled halfway and came to a juddering halt. The introduction of the euro led to deeper economic and political entanglement than the institutional structure of the time could bear. Complementary to the free movement of persons was a Common European Asylum System, the details of which were put into place procedurally between 1999 and 2013, but which lacked genuine cohesion: the Reception Conditions Directive allowed for extreme differences in national policies and a common refugee return policy was never agreed. The Common Foreign and Security Policy was established in 1993 but has never got off the ground. As a result, following earlier disagreements about the wars in former Yugoslavia and the Iraq War, the European Union has been unable to play an effective role either in the civil war in Syria or in the Ukrainian crisis.

6. Sahlins (1972).

7. In March 2017, during a discussion with Emmanuel Macron and Sigmar Gabriel, Habermas described this state of affairs as 'a furious standstill' (see: https://www.blaetter.de/archiv/jahrgaenge/2017/april/europa-neu-denken).

Open Access This chapter is licensed under the terms of the Creative Commons Attribution 4.0 International License (http://creativecommons.org/licenses/by/4.0/), which permits use, sharing, adaptation, distribution and reproduction in any medium or format, as long as you give appropriate credit to the original author(s) and the source, provide a link to the Creative Commons license and indicate if changes were made.

The images or other third party material in this chapter are included in the chapter's Creative Commons license, unless indicated otherwise in a credit line to the material. If material is not included in the chapter's Creative Commons license and your intended use is not permitted by statutory regulation or exceeds the permitted use, you will need to obtain permission directly from the copyright holder. 